\title{
Advanced Control of a High Power Converter Connected to a Weak Grid
}

\author{
Mahdi Shahparasti ${ }^{1}$, Pedro Catalán ${ }^{2}$, J. Ignacio Candela ${ }^{1}$, Alvaro Luna ${ }^{1}$, and Pedro Rodríguez ${ }^{1}$ \\ 1- Department of Electrical Engineering, Technical University of Catalonia, Barcelona, Spain \\ 2- Ingeteam Power Technology S.A., Zamudio, Spain \\ mshahparasti@yahoo.com, pedro.catalan@ingeteam.com, candela@ee.upc.edu, luna@ee.upc.edu; prodriguez@ee.upc.edu.
}

\begin{abstract}
This paper addresses the stability problems of a high power converter connected to a weak grid. The wide range values that grid impedance can take, challenges the stability and the performance of the controllers, which are responsible of regulating the current injection in such converters. In this work, a control strategy based on stationary reference frame controllers is selected and implemented using a proportional resonant (PR) controller, with capacitor voltage feedforward and a phase shifter. As it will be demonstrated in this paper, although the feedforward contributes to enhance the transient response of the converter, it may cause also deep unstable dynamics near to the medium frequency and decreases the phase margin in low frequency ranges. Therefore, it can be used to damp the unstable dynamics near to resonance frequency range and the LCL-filter can be adopted for the high frequency one. In order to improve the controller performance, a new phase shifter is added to the control scheme to enhance the phase margin at low frequency ranges. Simulation and experimental results considering weak grid conditions are shown to validate the proposed method.
\end{abstract}

Keywords- High power grid connected converter, resonance active damping, stability.

\section{INTRODUCTION}

Nowadays, high power Wind-Turbines (WTs) play an important role in the electric power system. The use of Voltage Source Converters (VSC) in current control mode is the most extended solution for connecting WTs to the grid [1]. The schematic in Fig. 1 shows the layout of a typical high power grid connected converter (GSC). In this system, a filter is necessary to reduce the harmonic content at the output of the converter. Typically, the filter is a low-pass configuration, whether LC or LCL filter are the most extended solutions [2].

Likewise, the equivalent Thevenin circuit of the power system at the point of common coupling (PCC) of the GSCs can be using for modelling the grid. In a typical PCC of a wind power plant, this equivalent circuit may count on a high impedance, as wind farms are normally located in remote areas, where the grid is prone to be weak. This impedance would be mainly inductive, and it varies depending on the power system configuration. No matter a LC or an LCL filter is used, the combination of the filter with the grid inductance gives rise to a LCL configuration.

Frequency response of LCL filter has a valley and one peak, the frequency associated to peak is referred as the resonance frequency [3]. In normal designs, the resonance frequency should be chosen between 10 bigger than the fundamental frequency $\left(f_{o}\right)$ and half of the switching frequency $\left(f_{s}\right)$. In converters with high frequency switching, the resonance frequency $\left(f_{r}\right)$ is far from the fundamental frequency, however in low frequency switching $f_{r}$ moves to values near to the $f_{o}$ with changing grid impedance, which leads to instability situations to the control system [4].

To damp the resonance peak, two methods have been proposed in literature: 1) passive damping, by adding some passive elements to LCL structure, and 2) active damping by changing the structure of the controller to increase the magnitude and phase margins around the resonance frequency. It is essential that both are robust with respect to the grid impedance variation. Passive damping decreases the overall system efficiency because of the losses related to passive elements. In addition, the ability of attenuating the switching harmonics is also weakened. On the other hand, active damping methods do not produce losses, but they are also more sensitive to parameter's variations [5]. In active damping, the feedback of voltage or current of the filter components is used to damp the resonance oscillation, and the extra power losses are avoided. In the literature, the concept of "virtual resistor" was proposed, based on the equivalent transformations of the mathematical model of the LCL gridconnected inverter [6]. In these works, it was pointed out that the active damping based on proportional capacitor current feedback was equivalent to a resistor in parallel with the filter capacitor. In this case the sampling frequency $f_{s w}$ must be larger than $2 f_{r}$ to ensure that the inverter is controllable in case of active damping with capacitor current, i.e., $\omega_{r} T_{s}<\pi$. This restriction is not always correct for high power GSCs, since they have low frequency switching. In this case, using a filter series with current controller is an effective method to damp resonance [7]. One of these filters can be used: 1) Lead-leg, 2) Notch filter and 3) Low pass filter. However, the cutoff frequency of these filters is set based on resonance frequency and it should be calculated on-line. The grid impedance is estimated in [8-9] to calculate $f_{r}$ online. However, these methods are finally complex and non-practical.

This paper presents a practical method for performing an active damping of the resonance. As it will be proven in this work, the feedforward of the capacitor voltage in the current loop permits to damp resonances, but decreases the phase 
margin. To take advantage of the characteristics of voltage feedforward and avoid its main drawback, a new phase shifter in stationary reference frame is proposed to increase the phase margin and to improve the stability.

\section{PROPOSED CONTROL STRATEGY}

As pointed out previously Fig. 1 shows the circuit diagram of a typical GSC. In Fig. 1, the converter control strategy consists of two control loops: an external current reference generator loop based on active and reactive power references, and an inner current control loop. This system is modelled in Fig. 3 and it can be mathematically described by the following transfer functions:

$$
\begin{aligned}
& i(s)=Y_{i}(s) V_{i}(s)+Y_{g}(s) V_{g}(s)= \\
& \frac{g_{i} e^{-s T_{d}}\left(s^{2} L_{g} C_{f}+r_{g} C_{f}+1\right)}{\Delta_{p}(s)} V_{i}(s)+\frac{-1}{\Delta_{p}(s)} V_{g}(s)
\end{aligned}
$$

$$
\begin{aligned}
& \Delta_{p}(s)=s^{3} L_{f} C_{f} L_{g}+s^{2} C_{f}\left(r_{f} L_{g}+r_{g} L_{f}+r_{d} L_{f}+r_{d} L_{g}\right) \\
& +s\left(C_{f}\left(r_{f} r_{g}+r_{d} r_{f}+r_{d} r_{g}\right)+L_{g}+L_{f}\right)+r_{f}+r_{g}
\end{aligned}
$$

Where $V_{i}(\mathrm{~s}), V_{g}(s), g_{i}$ and $i(s)$ are the converter output voltage, the grid voltage, the inverter gain and the converter output current, respectively. The delay of computation is modeled by $\exp \left(-s T_{d}\right)$, where $T_{d}$ is related to sampling time.

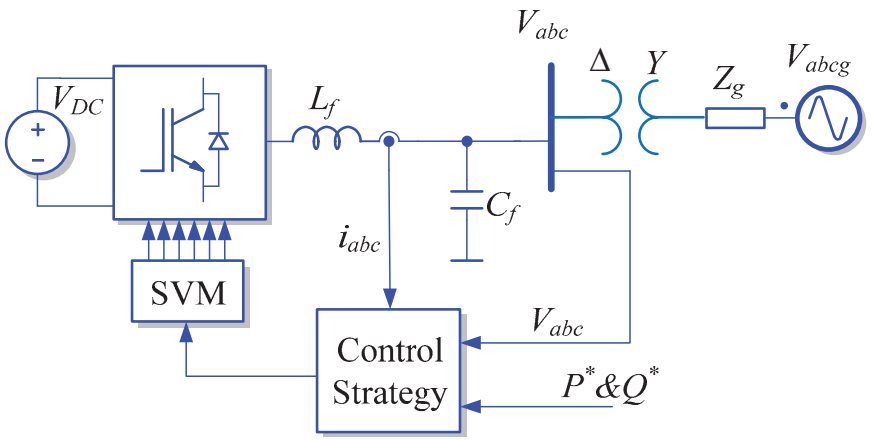

Fig. 1 Control strategy of Three-phase grid-connected inverter.

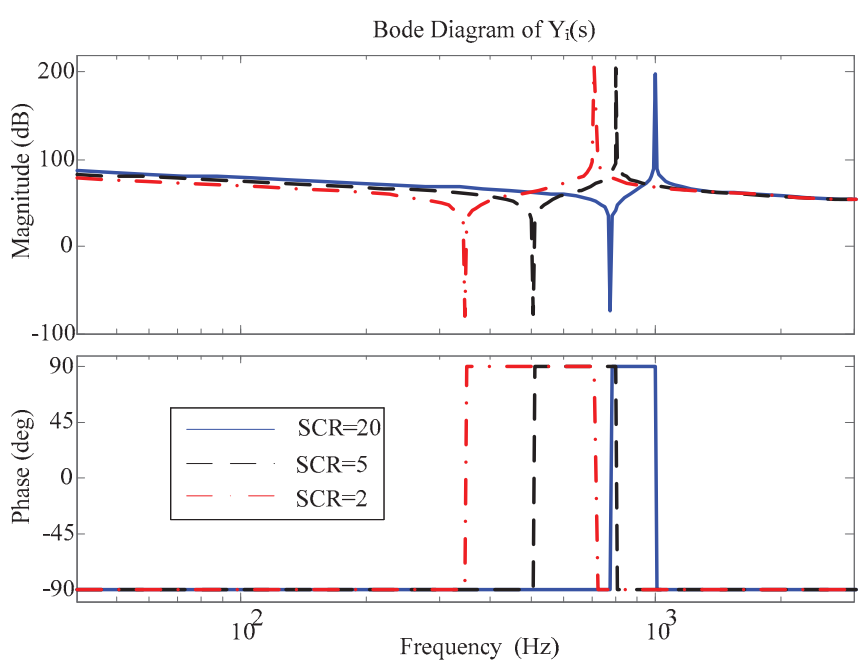

Fig. 2 System model response $\left(Y_{i}(S)\right)$ with $\mathrm{SCR}=2,5$, and 20.
Ignoring the resistors, the transfer functions in (1) will be simplified as follows [2]:

$$
\begin{gathered}
Y_{i}(s)=\frac{g_{i} e^{-s T_{d}}\left(s^{2}+\omega_{o}^{2}\right)}{s L_{f}\left(s^{2}+\omega_{r}^{2}\right)}, \\
Y_{i}(s)=\frac{g_{i} e^{-s T_{d}}\left(s^{2}+\omega_{o}^{2}\right)}{s L_{f}\left(s^{2}+\omega_{r}^{2}\right)}, \\
\omega_{r}=\sqrt{\left(L_{g}+L_{f}\right) /\left(L_{f} C_{f} L_{g}\right)}, \\
\omega_{o}=\sqrt{1 /\left(L_{f} C_{f}\right)},
\end{gathered}
$$

where $\omega_{\mathrm{r}}$ and $\omega_{\mathrm{o}}$ are the resonance frequency and antiresonance frequency, respectively. The zeros in the transfer function of $Y_{i}(s)$ leads to a negative peak at $\omega_{\mathrm{o}}$ and cause less damping and phase lag at frequencies above $\omega_{\mathrm{r}}$ as they compensate the effect of two poles. Fig. 2 shows frequency response of $Y_{i}(s)$. In Fig. 2, by increasing $L_{g}$, decreasing thus the short circuit ratio (SCR), valleys and peaks appear at lower frequencies. In most of the cases, the magnitude of the filter response is constant at low frequencies. However, in this system due to the changing of $L_{g}$, this principle is violated and the system may be unstable, since the resonance frequency moves close to fundamental frequency when the impedance of grid is increased.

The proposed control strategy is shown in Fig. 3. The voltage of the capacitors and the converter's currents are measured to control the grid-connected inverter. As shown in the figure, the delay of the transducers are modeled as a first order low pass filters. In the outer loop, the current reference is generated and then tracked by proportional resonant (PR) controllers. A non-pure resonant term with resonance bandwidth $\omega_{c}=2 \mathrm{rad}$ is used in PR controller to avoid stability problems. In addition, the voltage feedforward is used to damp unstable dynamics. To carry out the design of the controller, the system model with voltage feedforward can be simplified as shown in the following.

$$
\begin{aligned}
& i(s)=Y_{i}^{\prime}(s) V_{i}^{\prime}(s)+Y_{g}^{\prime}(s) V_{g}(s), \\
& Y_{i}^{\prime}(s)=\frac{e^{j \phi_{c}} e^{-s T_{d}}\left(s^{2} L_{g} C_{f}+C_{f}\left(r_{g}+r_{d}\right)+1\right)}{\Delta(s)}, \\
& Y_{g}^{\prime}(s)=\frac{\left(1+s r_{d} C_{f}\right)\left(\left(1-k_{f} e^{j \phi_{c}} e^{-s T_{d}}\right)+s T_{v}\right)}{\Delta(s)}, \\
& \Delta(s)=s^{4} L_{f} C_{f} L_{g} T_{v}+ \\
& s^{3}\left(L_{f} C_{f} L_{g}+T_{v} C_{f}\left(r_{g} L_{f}+r_{d}\left(L_{f}+L_{g}\right)\right)\right)+ \\
& s^{2}\left(\begin{array}{l}
C_{f}\left(r_{g} L_{f}+r_{d} L_{f}+r_{d} L_{g}\right)+T_{v}\left(r_{g} r_{d} C_{f}+L_{f}+L_{g}\right) \\
-k_{f} e^{j \phi_{c}} e^{-s T_{d}} r_{d} C_{f} L_{g}
\end{array}\right)+ \\
& s\left(\left(1-k_{f} e^{j \phi_{c}} e^{-s T_{d}}\right)\left(r_{g} r_{d} C_{f}+L_{g}\right)+r_{g} T_{v}+L_{f}\right)+r_{g}\left(1-k_{f} e^{j \phi_{c}} e^{-}\right.
\end{aligned}
$$




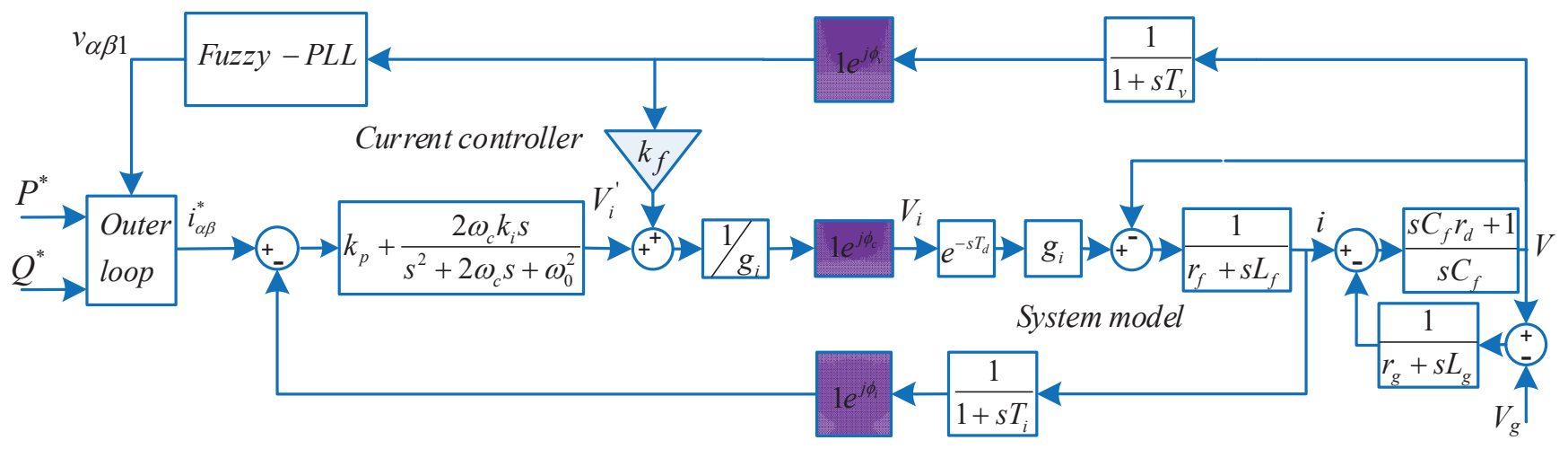

Fig. 3 System model and control strategy

Where $V_{i}^{\prime}(s)$ and $r_{d}$ are the output of the current controller and the series resistance with the capacitor. Based on the above equation and routh-hurwitz criterion, the voltage feedforward $\left(k_{f}\right)$ gain must be lower than 1.

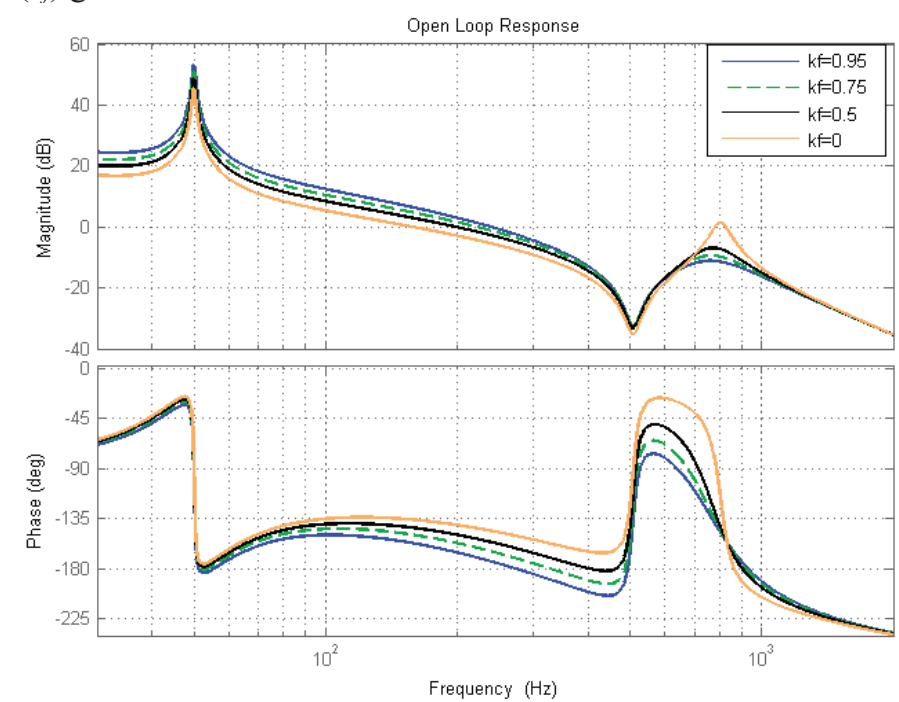

Fig. 4 Bode diagrams for $\mathrm{SCR}=5$. Open loop response.

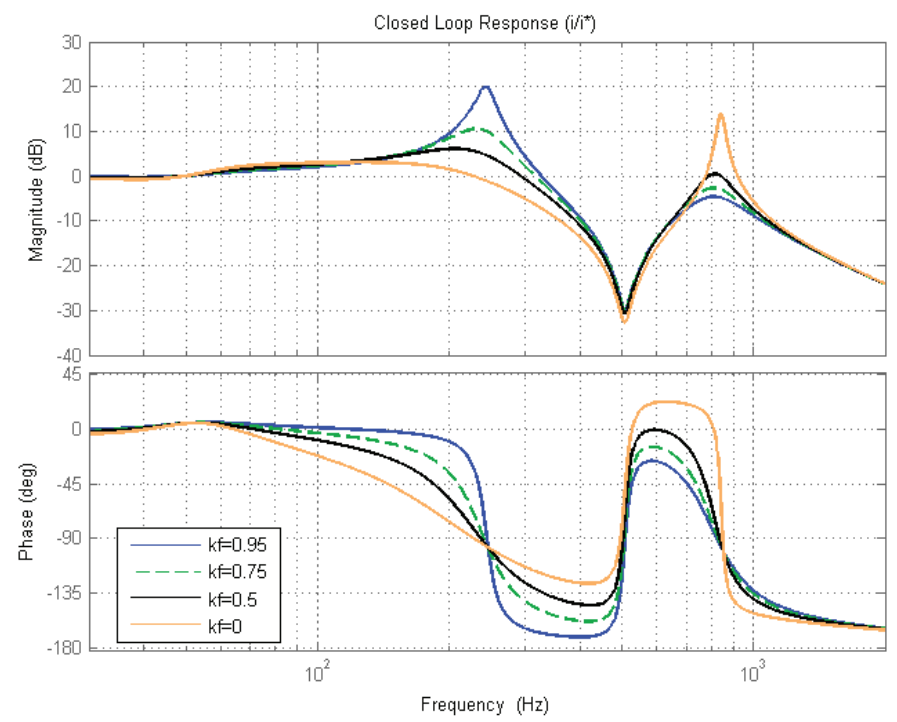

Fig. 5 Bode diagrams for $\mathrm{SCR}=5$ : Closed loop response.

To find the proportional coefficient $\left(\mathrm{k}_{\mathrm{p}}\right)$ of the PR controller, the phase margin and bandwidth criteria will be used.

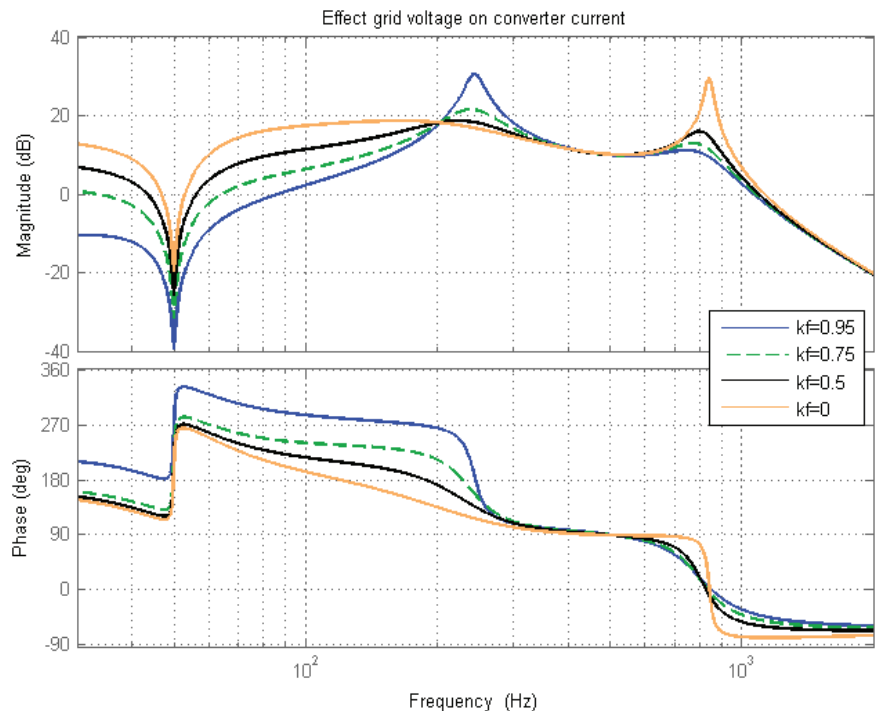

Fig. 6 Bode diagrams for $\mathrm{SCR}=5$ : Effect of the grid voltage on the converter current.

As the crossover frequency $f_{c}$ is usually set to be lower than the $10 \%$ of the equivalent switching frequency, considering the effect of the high-frequency noise, the cutoff frequency filter $f_{r}$ is usually designed in the region from $25 \%$ to $50 \%$ of equivalent switching frequency to ensure effective harmonics suppression and well dynamic response. Finally, the resonant coefficient $\left(k_{i}\right)$ of PR controller is selected based on steady state error in fundamental frequency.

In Fig. 4, the open loop response, the closed loop response and the effect of the grid voltage on the converter's current are shown for $k_{p}=1.5, k_{i}=80$ and $\mathrm{SCR}=5$. From the steady-state error and resonant coefficient point of view, the magnitude of the open loop response in $f_{o}=50 \mathrm{~Hz}$ is bigger than $50 \mathrm{~dB}$, thus the steady state error of tracking in $f_{o}=50 \mathrm{~Hz}$ is lower than $1 \%$. By selecting properly the proportional coefficient and feedforward gain the following requirements can be covered: fast dynamic response, high stability margin and resonance elimination. However, it is necessary to make an appropriate trade-off. It can 
be seen from Fig. 4-a, in open loop response, that increasing the feedforward gain leads to increase the bandwidth, decrease the phase margin (PM) and attenuate the resonance. The reduction of the PM leads to the creation of a peak around the cutoff frequency in the closed-loop response, as shown in Fig. 5. On the other hand, by increasing the feedforward gain, the magnitude around the cutoff frequency and the resonance frequencies get amplified

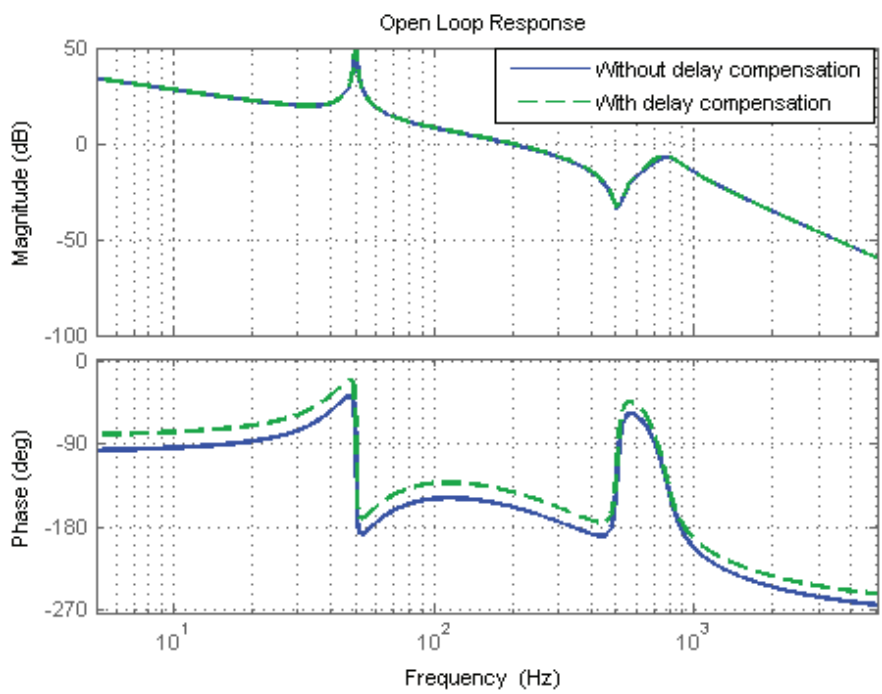

Fig. 7 Bode diagrams for $\mathrm{SCR}=5$ with phase shifter: Open loop response.
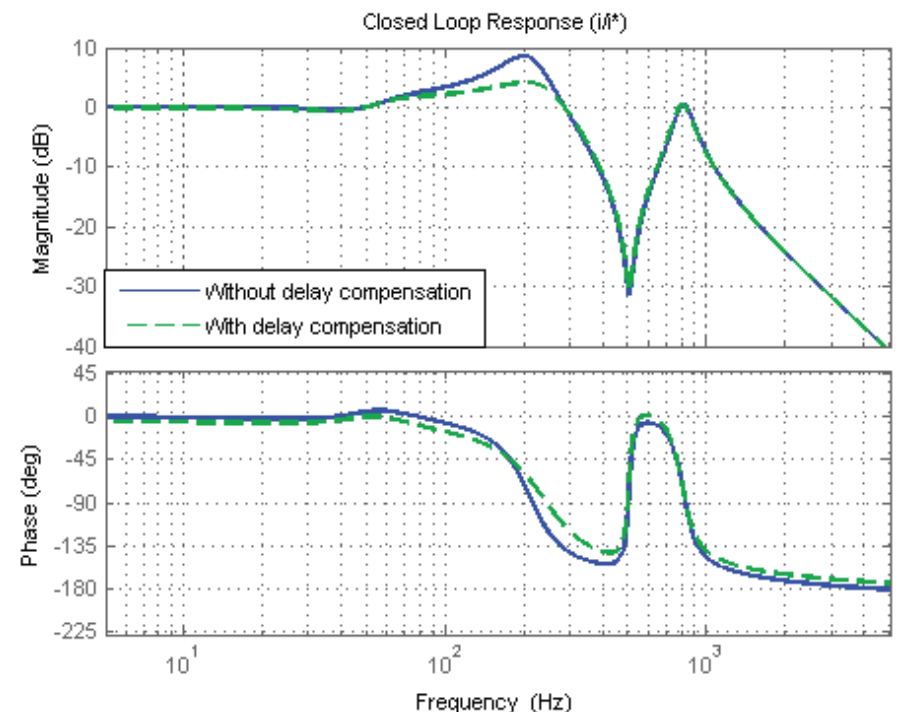

Fig. 8 Bode diagrams for $\mathrm{SCR}=5$ with phase shifter: Closed loop response.

and dropped off, respectively. In Fig. 6 the effect of the grid voltage on the converter's current is shown. In this case it can be seen that the voltage feedforward can be used to reject the disturbances around the fundamental and resonant frequencies. However, if the feedforward gain is increased, the grid voltage will have a significant impact on the current of the converter. The cutoff frequency range is from 200 to $250 \mathrm{~Hz}$. As a result, the grid voltage harmonics effects will be greater on converter's current in this area.

Therefore, it can be concluded from Fig. 4 until Fig. 6 that the voltage feedforward has dual behavior and it must be selected based on a compromise between stability and resonance elimination. The constraints for the feedforward gain selection are: 1) system becomes unstable without voltage feed forward due to occurrence of resonance in low SCRs, 2) when the feedforward gain increases, the peak amplitude of the resonance will be declined. However, by increasing the feedforward gain, some peaks are created around the cutoff frequency in the closed loop response due to the reduction of phase margin in the open loop response. Therefore, the best value for the feedforward gain is around 0.5 by taking into account the constraints in open loop response, close loop response and effect of grid voltage on current bode diagrams.

A new phase shifter is proposed in (10) to increase phase margin and to improve stability:

$$
1 e^{j \phi}=\left[\begin{array}{cc}
\cos \phi & -\sin \phi \\
\sin \phi & \cos \phi
\end{array}\right],
$$

This phase shifter used between current controller and SVM modular improves system phase margin. In addition, this phase shifter can be used to compensate the delay in feedback branches to improve the overall system's performance. The delay of the transducers are eliminated by adding phase shifter to the feedback of the current and the voltage in this Fig. 3. The effect of using phase shifters on bode diagrams are shown in Fig. 7 until Fig. 9 . In open loop response, it leads to a small increase in the bandwidth, but the improvement of the phase margin (PM) is significant. It should be mentioned that it does not have any effect on the resonance. According to Fig. 8, the improvement of PM weakens the peak of magnitude around the cutoff frequency in the closed-loop response. Also in Fig. 9, it decreases the magnitude around the bandwidth frequency $(200 \mathrm{~Hz})$.

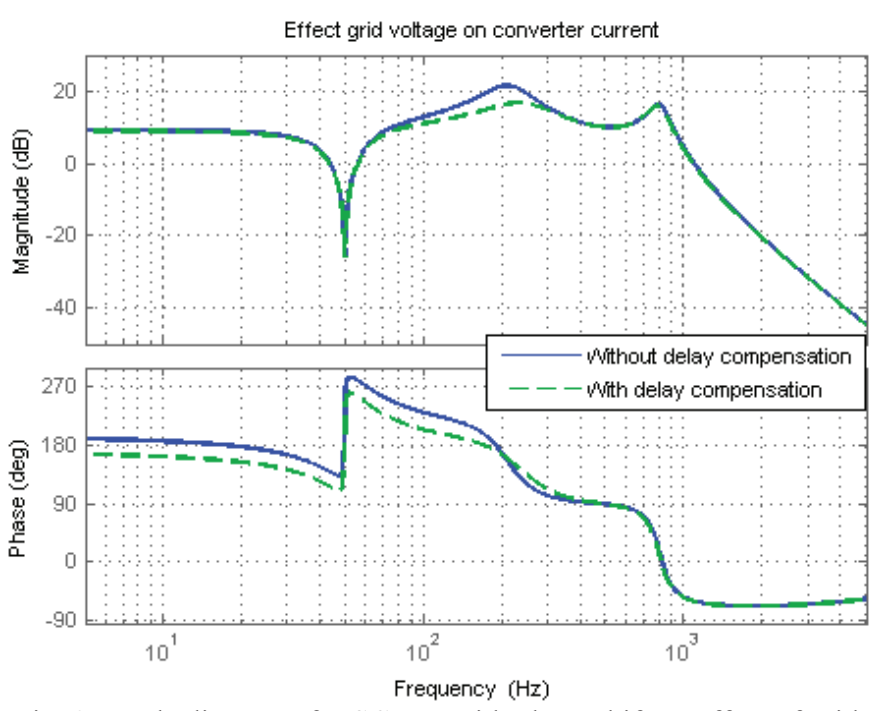

Fig. 9 Bode diagrams for $\mathrm{SCR}=5$ with phase shifter: Effect of grid voltage on converter current. 
TABLE I SIMULATION PARAMETERS

\begin{tabular}{|c|c|c|c|}
\hline \hline Variable & Value & Variable & Value \\
\hline$V\left(\mathrm{~V}_{\text {rms }}\right)$ & 400 & $C_{\mathrm{F}}(\mu \mathrm{F})$ & 1000 \\
\hline $\mathrm{S}_{\mathrm{NOM}}(\mathrm{VA})$ & $4 \mathrm{M}$ & $f_{\mathrm{o}}(\mathrm{Hz})$ & 50 \\
\hline$V_{\mathrm{DC}}(\mathrm{V})$ & 1150 & $f_{\mathrm{S}}(\mathrm{kHz})$ & 2 \\
\hline$L_{\mathrm{F}}(\mathrm{uH})$ & 65 & & \\
\hline
\end{tabular}
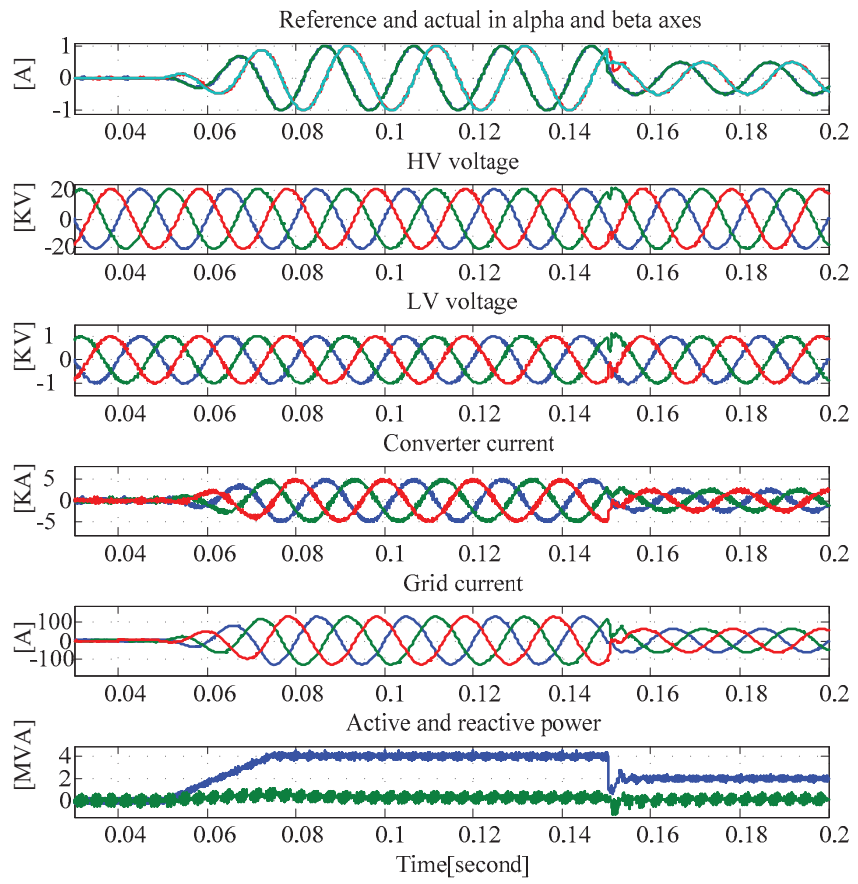

(a)
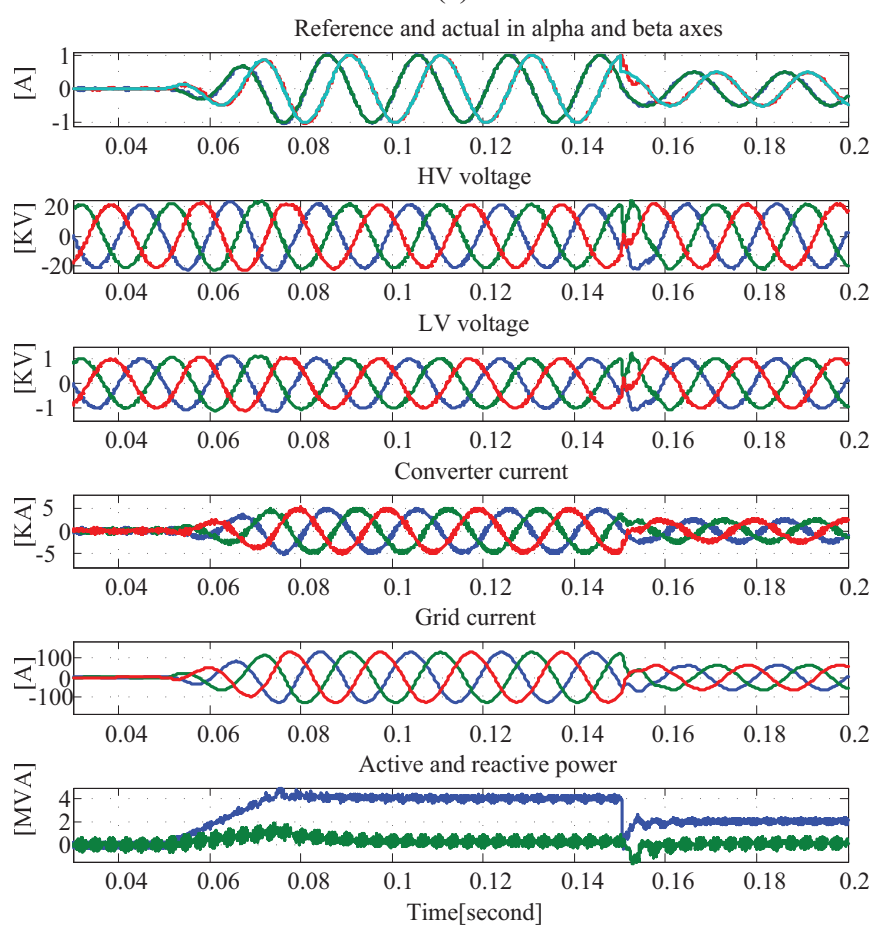

(b)

Fig. 10 Simulation results for (a) $\mathrm{SCR}=20$ (b) $\mathrm{SCR}=3$. From up: Current reference and actual current in alpha and beta axes, grid voltage (high voltage side of transformer), capacitors voltages (low voltage side of transformer), converter current, grid current, converter output power.

\section{SIMULATION RESULTS}

The time-domain simulation studies are done in the MATLAB environment to evaluate the performance of the proposed control scheme. The parameters of 4MVA GSC are listed in Table. I. The GSC consists of an inverter bridge with six IGBTs and a three-phase grid-interfaced inductor and capacitor. The dc-link voltage of the inverter is fixed to be 1150 VDC. The GSC is connected to the grid through a Dyn $690 / 25 \mathrm{kV}$ 4.4MVA three-phase transformer. This system will be simulated with several SCR. Three intervals are defined in simulation: Form $\mathrm{t}=0$ until $\mathrm{t}=0.05$ second, the active power reference is $0 \mathrm{~W}$. At $\mathrm{t}=0.05$ second, the active power reference changes 0 to $4 \mathrm{MW}$, then the active power changes from $4 \mathrm{MW}$ to $2 \mathrm{MW}$ at $\mathrm{t}=0.15$ second. The active reference power is increased by $160 \mathrm{MW} /$ second rate and it is decreased immediately following a step. The reference of reactive power in this case is zero.

The simulation results are shown in Fig. 6. The current reference and actual current in alpha axis and beta axis, HV side voltage, LV side voltage, converter current, grid current and converter output power are shown.

In the first simulation, the converter is connected to a stiff grid with a $\mathrm{SCR}=20$. In Fig.6-a, power and current references are tracked with zero steady state error and acceptable transient response. From the frequency spectrum of the grid current and HV side voltage it can be found that the THD of HV side voltage is about $2.53 \%$ and THD of grid current is about $1.74 \%$ that comply with standards.

In the next simulation, the converter is connected to a weak grid with a $\mathrm{SCR}=3$. The simulation results are shown in Fig. 6 -b. In this figure it is shown how references of power and current are tracked with good performance. In this case the transient response is slower than $\mathrm{SCR}=20$. The THD of the HV side voltage is about $4.07 \%$ and the THD of grid current is about $0.76 \%$, which comply with the standards. The most dominant harmonic components are the sidebands of the switching frequency.

In both SCRs, the amplitude of the PCC voltage about resonance frequency is lower than $0.5 \%$ due to active damping of voltage feedforward. Thus, the possibility of having resonance phenomena is low.

The converter has large ripples current due to low switching frequency. According to Fig. 7, current components have salient magnitudes in sideband of the switching frequency.

To evaluate of the simulation results, the equivalent circuit of the GSC is shown in Fig. 8, where $L_{o}$ is inductance due to control strategy. When the grid is pure sinusoidal, the PCC voltage in harmonics can be expressed as:

$$
\begin{gathered}
V_{a b c}=\left(s L_{f}\left\|1 / s C_{f}\right\| s L_{g}\right) \times i_{h} \quad s \neq 2 \pi f \\
L_{g}=\frac{V_{n}^{2}}{2 \pi f \times S C R \times S_{n}}
\end{gathered}
$$

where $S_{n}, \mathrm{SCR}$ and $V_{n}$ are the converter nominal power, short circuit ratio and nominal voltage, respectively. The harmonic components of the converter current for different 
SCR are constant. When the SCR of network decreases, the voltage at the PCC becomes more distorted because the equivalent impedance in the PCC point is increased. In other hand, the quality of the grid current is improved because of the fact that the converter current harmonics around the switching frequency are further weakened by the filter.

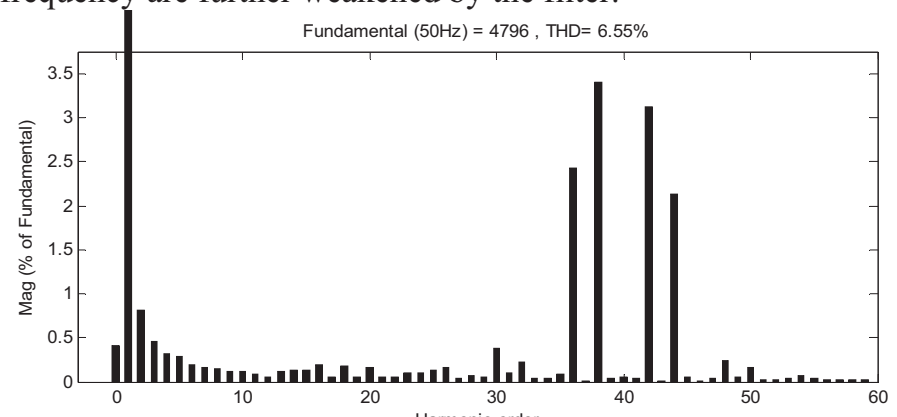

Fig. 11 Frequency spectrum of converter current.
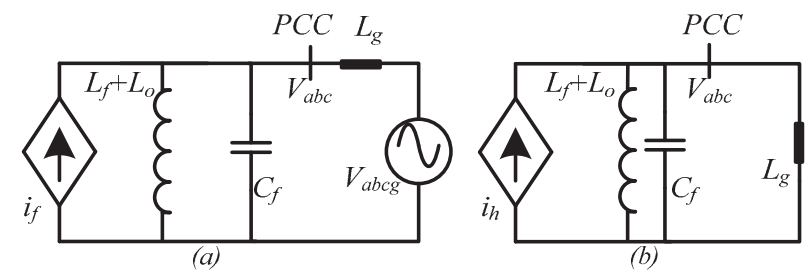

Fig. 12 Simplified model of GSC. (a) In fundamental frequency. (b) In harmonics.

\section{EXPERIMENTAL RESULTS}

The experimental performance of the control strategy has been tested as well in an experimental platform, as shown in Fig. 13. The values of the different parameters involved in the experiment are detailed in the Table II.

TABLE II EXPERIMENTAL PARAMETERS

\begin{tabular}{|c|c|c|c|}
\hline \hline Variable & Value & Variable & Value \\
\hline$V_{\mathrm{O}}\left(\mathrm{V}_{\text {rms }}\right)$ & 220 & $C_{\mathrm{F}}(\mu \mathrm{F})$ & 10 \\
\hline S $_{\text {NOM }}(\mathrm{VA})$ & $10 \mathrm{KVA}$ & $f_{\mathrm{O}}(\mathrm{Hz})$ & 50 \\
\hline$V_{\mathrm{DC}}(\mathrm{V})$ & 650 & $f_{\mathrm{S}}(\mathrm{kHz})$ & 10 \\
\hline$L_{\mathrm{F}}(\mathrm{mH})$ & 2.43 & & \\
\hline
\end{tabular}

The control strategy as shown in Fig.4 is implemented by using Digital Signal Processor (DSP) TMS320F28835, the experimental results are shown in

Fig. 14 until

Fig. 15.

In

Fig. 14 the transient response of a step up of current reference from 0 to 1 p.u. is shown. It can be seen the current reference is tracked after 0.005 second with zero steady state error.

The experimental results for step down reference current from 1p.u. to zero p.u. are shown at

Fig. 15. It can be seen that the converter current changes from nominal current to zero immediately. Therefore, it can be concluded that the controller has an acceptable response in the aspect of steady state and transient responses.

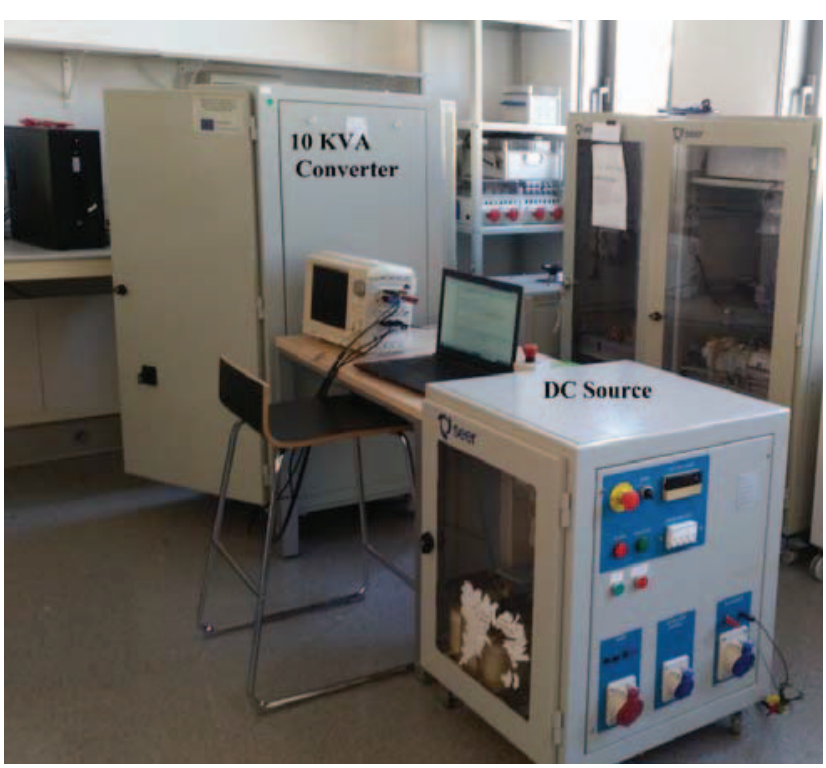

Fig. 13 Experimental test bed employed in the experiments.

The harmonic spectrum of converter current and grid current are shown in Fig. 16 and Fig. 17, respectively. THD of converter current is about $4.85 \%$ and amplitude of 5th harmonic and $7^{\text {th }}$ harmonic is lower than $2 \%$ which complies with the standards. The THD of the grid current is about $3.14 \%$ which is lower $5 \%$.

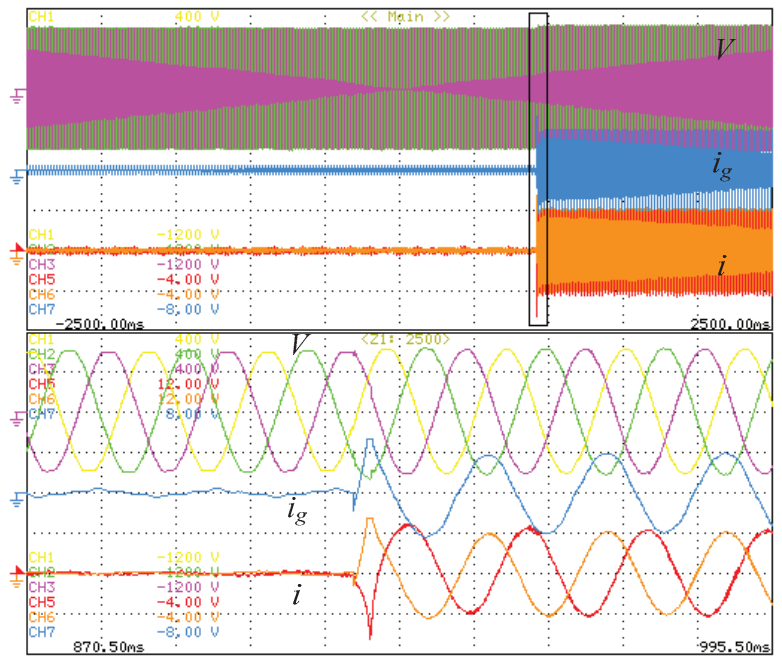

Fig. 14 Experimental results. Transient response, the current reference changes from zero to 1 p.u. From up: Capacitors voltages, Grid current, and converter current. Scale is set to $200 \mathrm{~V} /$ div in voltage variables, and $20 \mathrm{~A} /$ div for current in all the graphs.

\section{CONCLUSIONS}

This paper proposes a proportional resonant controller to control high power three-phase grid-connected inverter with LC filter. To implement a LCL filter, the inherent impedance of the grid is used as a second inductance of the LCL filter. 
The limitations of improving transient and steady state responses of PR controller are investigated. It has been shown that the LCL filter permits to provide the proper attenuation of sideband voltage harmonics.

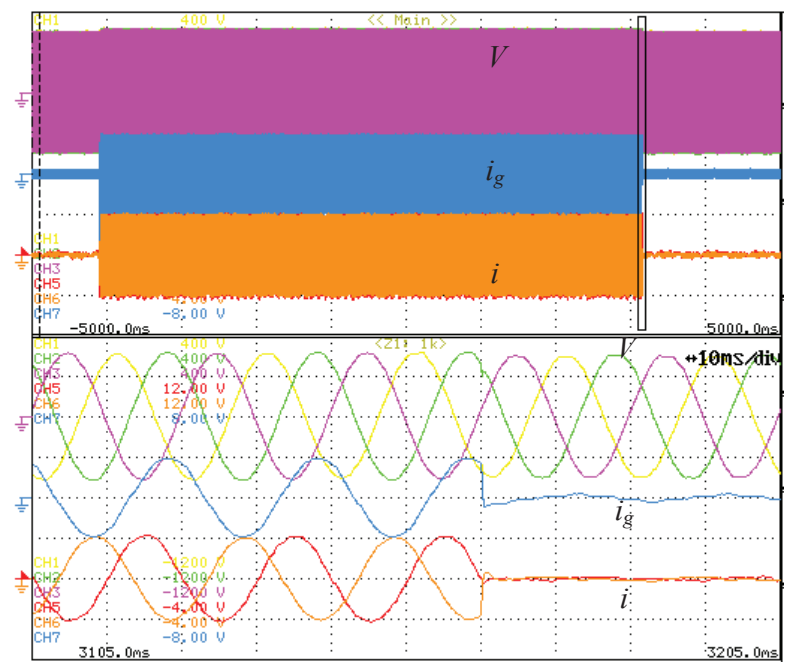

Fig. 15 Experimental results. Transient response, the current reference changes from 1p.u. to 0 p.u. From up: Capacitors voltages, Grid current, and converter current. Scale is set to $200 \mathrm{~V} / \mathrm{div}$ in voltage variables, and $20 \mathrm{~A} /$ div for current in all the graphs.
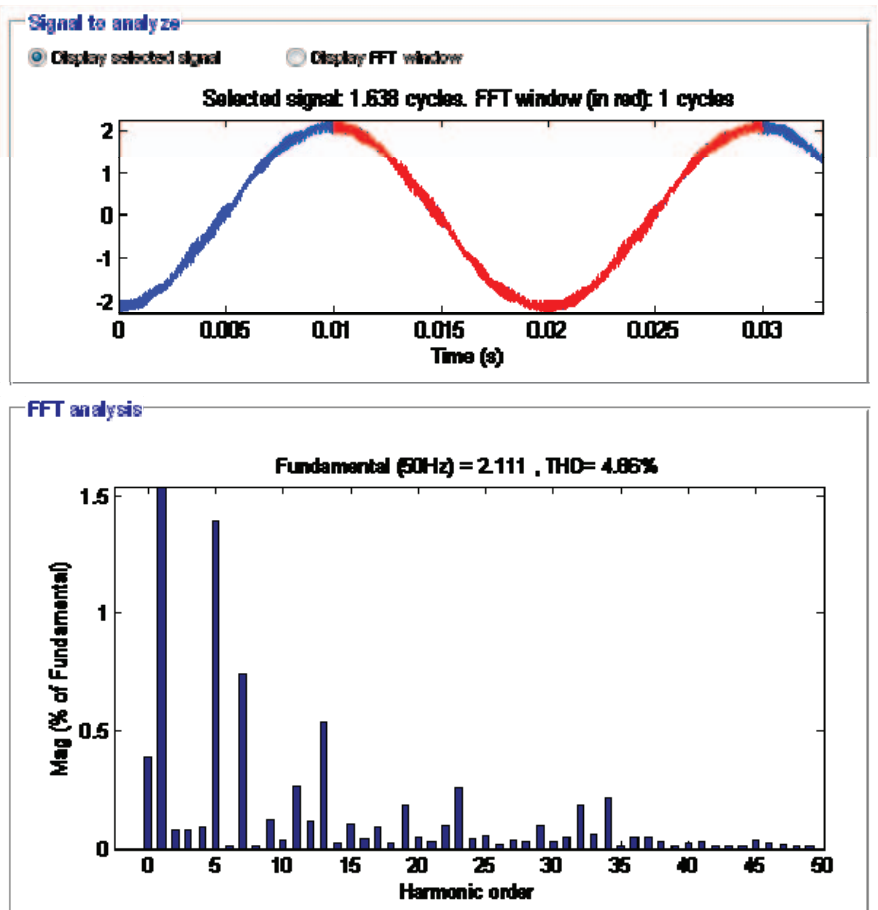

Fig. 16 The harmonic spectrum of converter current.

However, those grid filters introduce potentially unstable dynamics that should be properly damped either passively or actively. By proposing the voltage feedforward and phase shifter in control strategy, it is able to damp the unstable dynamics and to improve the phase margin, respectively.
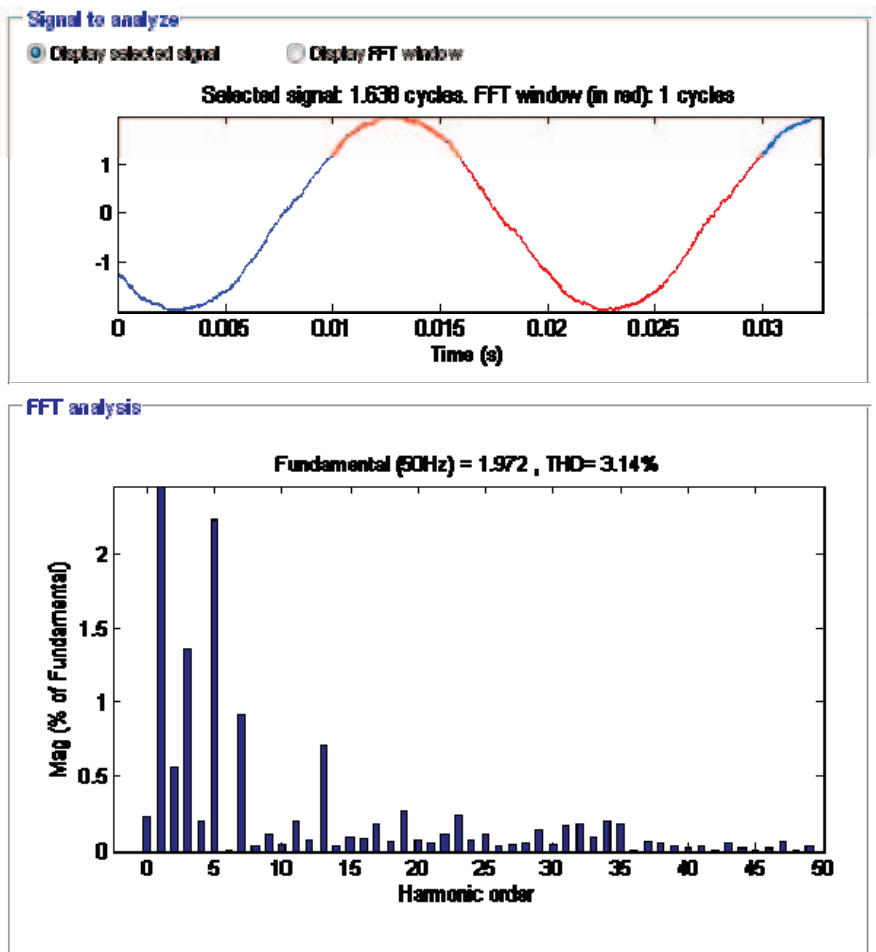

Fig. 17 The harmonic spectrum of grid current.

\section{ACKNOWLEDGMENT}

The Spanish Ministry of Economy and Competitiveness has supported this work under the projects RTC-2014-1824-3 \& ENE2014-60228-R.

\section{REFERENCES}

[1] A. Abrantes, "Overview of power quality aspects in wind generation," 2012 North Am. Power Symp., vol. 80521, no. 2, pp. 1-6, 2012.

[2] M. Liserre, R. Teodorescu, and F. Blaabjerg, "Stability of photovoltaic and wind turbine grid-connected inverters for a large set of grid impedance values," IEEE Trans. Power Electron., vol. 21, no. 1, pp. 263-271, 2006.

[3] A. Ghoshal and V. John, "Active damping of LCL filter at low switching to resonance frequency ratio," IET Power Electron., vol. 8, no. 4, pp. 574582, 2015.

[4] Y. Tang, P. C. Loh, P. Wang, F. H. Choo, and F. Gao, "Exploring inherent damping characteristic of LCL-filters for three-phase grid-connected voltage source inverters," IEEE Trans. Power Electron., vol. 27, no. 3, pp. 1433-1443, 2012.

[5] X. Wu, X. Li, X. Yuan, and Y. Geng, "Grid Harmonics Suppression Scheme for LCL -Type Grid-Connected Inverters Based on Output Admittance Revision," IEEE Trans. Sustain. Energy, vol. 6, no. 2, pp. 411$421,2015$.

[6] X. Wang, F. Blaabjerg, and P. C. Loh, "Virtual RC Damping of LCL Filtered Voltage Source Harmonic Compensation," IEEE Trans. Power Deliv., vol. 30, no. 9, pp. 4726-4737, 2015.

[7 ]J. Dannehl, M. Liserre, and F. W. Fuchs, "Filter-based active damping of voltage source converters with LCL filter," IEEE Trans. Ind. Electron., vol. 58 , no. 8, pp. 3623-3633, 2011.

[8] M. Liserre, F. Blaabjerg, and R. Teodorescu, "Grid impedance estimation via excitation of LCL-filter resonance," IEEE Trans. Ind. Appl., vol. 43, no. 5, pp. 1401-1407, 2007.

[9] R. Pe, M. Liserre, F. Blaabjerg, and T. Kerekes, "Self-commissioning Notch Filter for Active Damping in Three Phase LCL -filter Based Grid-tie Converter," IEEE Trans. Power Electron., vol. 8993, no. c, pp. 1-9, 2014. 